\title{
Understanding the Habitat Needs of the Declining Western Yellow-Billed Cuckoo
}

\section{$\mathrm{T}$}

he western yellow-billed cuckoo, once common along the streams and rivers of the American West, is now a candidate for protection under the Endangered Species Act. Most of the remaining breeding pairs are found in Arizona, California, and New Mexico. Research to understand the cuckoos' habitat needs by U.S. Geological Survey (USGS) and Northern Arizona University scientists has shown that cuckoos in Arizona prefer breeding habitat dominated by native tree species, especially cottonwood-willow habitat bordered by mesquite bosque habitat. This research also revealed that the size of habitat patches matters-breeding cuckoos were found only in large, continuous areas of riparian habitat. These findings and the development of spatially explicit habitat models by USGS scientists will help resource managers conserve and manage riparian habitats needed to ensure the survival of the western yellow-billed cuckoo.
The western yellow-billed cuckoo (Coccyzus americanus occidentalis) is a shy neotropical migrant bird; its loud "ka, ka, ka, ka, ka, kow, kow, kow" call is often the only evidence that this reclusive bird is present. Traveling from their winter homes in South America, the birds arrive in the Western United States to breed from early June to late August in vegetated areas along rivers and streams. Once common between the Rocky Mountains and the Pacific Ocean and from lower British Columbia, Canada, south to northern Mexico, western cuckoos have now disappeared from the Pacific Northwest and Canada, and only a few pairs still breed in Utah, Idaho, Colorado, and Nevada. Most breeding occurs in isolated areas along rivers in Arizona, California, and New Mexico.

Because relatively little is known about the life history and habitat needs of the western

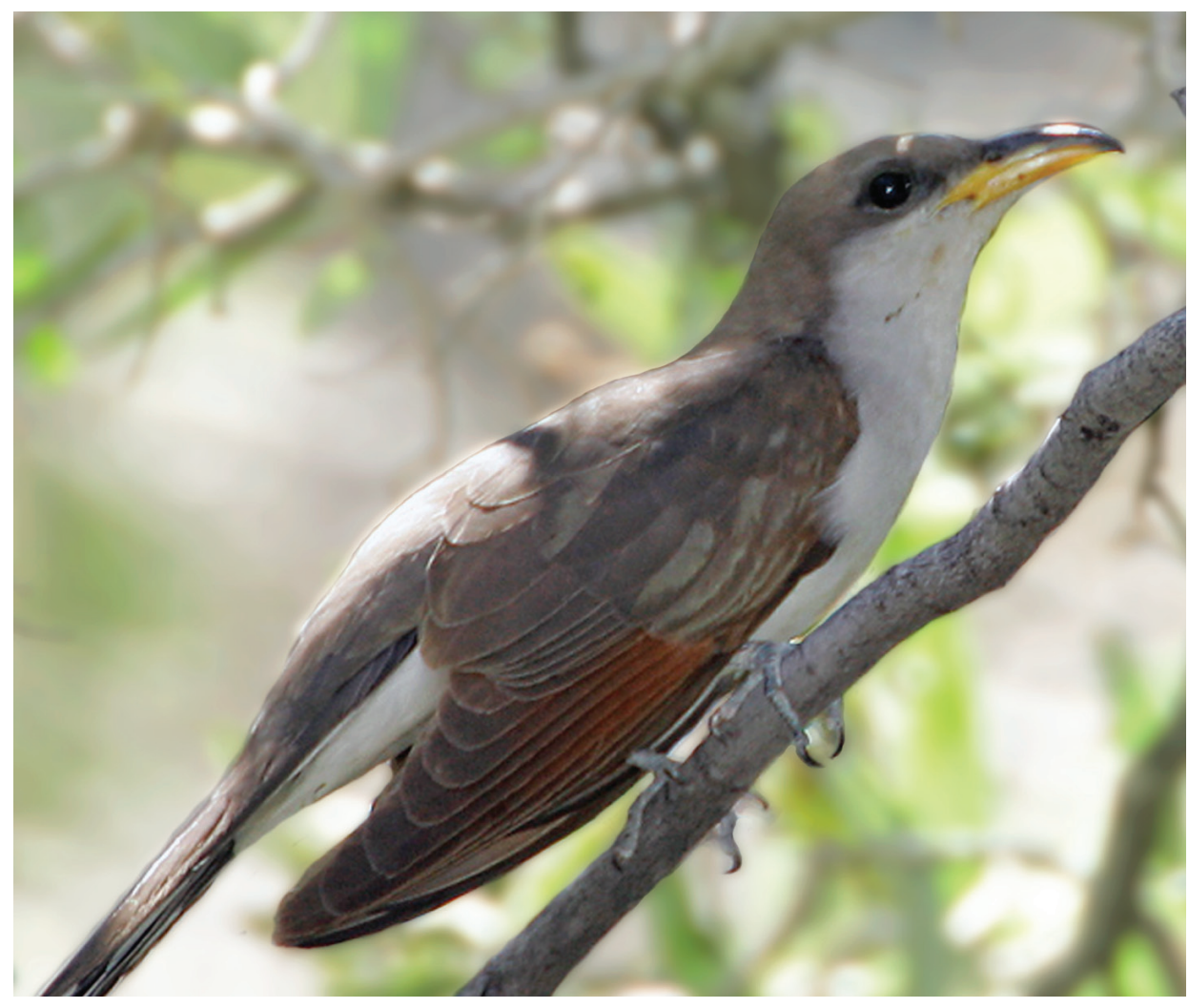

An adult western yellow-billed cuckoo (Coccyzus americanus occidentalis), a candidate for protection under the Endangered Species Act. U.S. Geological Survey scientists have undertaken research to understand the bird's specific habitat needs. (Photograph (C) Bob Steele/VIREO.)

yellow-billed cuckoo, U.S. Geological Survey (USGS) and Northern Arizona University scientists have been studying this bird along the lower Colorado River in Arizona and California. Although the lower Colorado River represents some of the best remaining cuckoo habitat in that region, a previous study estimated that cuckoo populations there declined by $93 \%$ between 1976 and 1986. By 1998, USGS scientist were unable to locate any yellow-billed cuckoo pairs in the parts of California west of the Colorado River that had been occupied in 1976 and 1977.

The decline of the western yellow-billed cuckoo coincides with the growth of human populations in the West and the loss of riparian habitat (habitat near a waterway) resulting from increased development, agriculture, and dam building. In Arizona, it has been estimated that during the past 300 years riparian ecosystems have declined from approximately $5 \%$ of the State's landmass to $1 \%$.

In 2001, as the result of habitat loss, the U.S. Fish and Wildlife Service found that the western yellow-billed cuckoo (that is, populations west of the crest of the Rocky Mountains) represents a distinct population segment and warrants protection under the Endangered Species Act. It was determined that the western yellow-billed cuckoo should be listed as "threatened," but this action was precluded by other higher priority listing actions. As of 2009 , the western yellow-billed cuckoo is still a candidate for listing under the act.

\section{Research Findings}

In 1998 and 1999, USGS scientists worked with the Arizona Game and Fish Department to locate cuckoo populations 


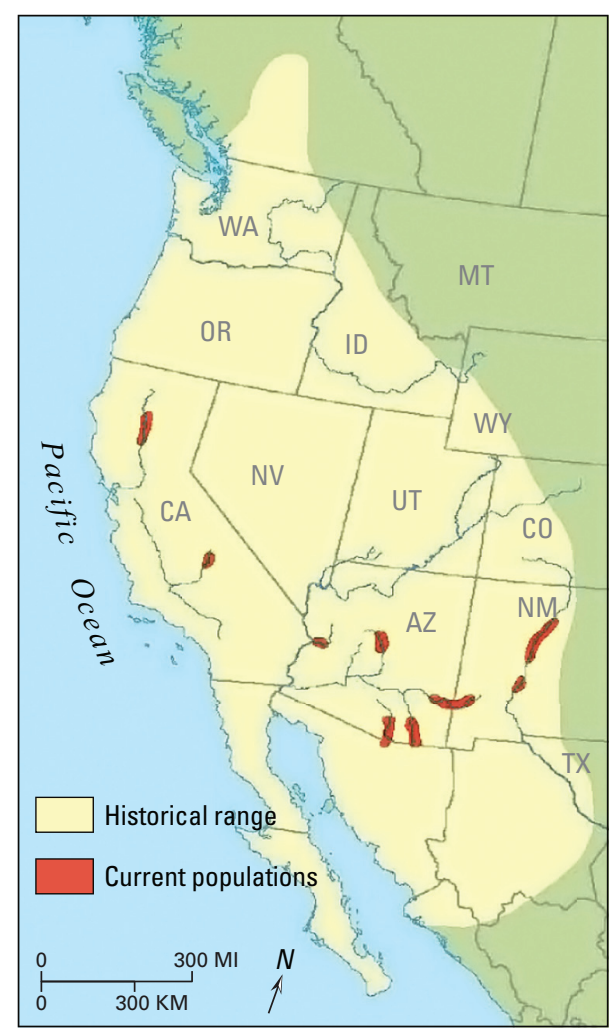

Historical and current distributions of the western yellow-billed cuckoo.

throughout Arizona. Cuckoos were found primarily along the Agua Fria, San Pedro, and Verde Rivers, Cienega and Sonoita Creeks, and the Bill Williams River, a tributary to the lower Colorado River. Additional surveys done from 2005 to 2007 indicated that $85 \%$ of the cuckoos detected in the lower Colorado River Basin were found at Bill Williams National Wildlife Refuge, Arizona (Johnson and others, 2008), where the highest quality cuckoo habitat in the region still exists.

The breeding cuckoos found along the Bill Williams River were nesting in riparian habitat dominated by native tree species, particularly cottonwoods and willows; cuckoos did not breed in small, isolated patches or in areas dominated by exotic vegetation such as tamarisk. In addition to patch size, the vegetation that surrounds a patch may influence whether cuckoos use a site. Additional research conducted in central Arizona showed that cuckoos were most often found in cottonwood-willow habitat bordered by mesquite bosque habitats (Holmes and others, 2008).

Scientists also found that sites occupied by cuckoos generally had taller trees, thicker cover in the upper and middle layers of the canopy, and sparser shrub layers than unoccupied sites. Unoccupied sites consistently had very little canopy and higher densities of small trees, mostly nonnative tamarisk. Cuckoos may prefer riparian areas that are dominated by native species with a multistoried structure and high, dense canopies for nesting and an open understory for foraging.

Scientists have hypothesized that the cuckoo is restricted to moist river bottoms to meet humidity levels required for successful breeding. To examine this idea, scientists measured microclimate variables - temperature and relative humidity - along the lower Colorado River at occupied and unoccupied sites. Sites occupied by cuckoos were consistently cooler during the day and more humid during both day and night than unoccupied sites.

Changing environmental factors also affect cuckoo habitat - sometimes rapidly. In 2006, surveys conducted in Lake Mead National Recreation Area, Arizona and Nevada, detected many pairs of breeding cuckoos in the area where the Colorado River flows into the lake, an area known as the Lake Mead delta. A year later, in 2007, scientists detected no cuckoos in the delta. Many of the native trees where cuckoos bred in 2006 had died or were dying in 2007. The native tree die off occurred during an ongoing drought, which dropped the water level of Lake Mead by approximately 15 feet from 2006 to 2007 . Dead trees, or snags, increased from 14 to

\begin{abstract}
Habitat used by breeding western yellow-billed cuckoos along the Bill Williams River in Arizona. The birds nest almost exclusively near water in large, continuous patches of native woodlands with cottonwoods and willows. (USGS photograph by Matthew J. Johnson.)
\end{abstract}

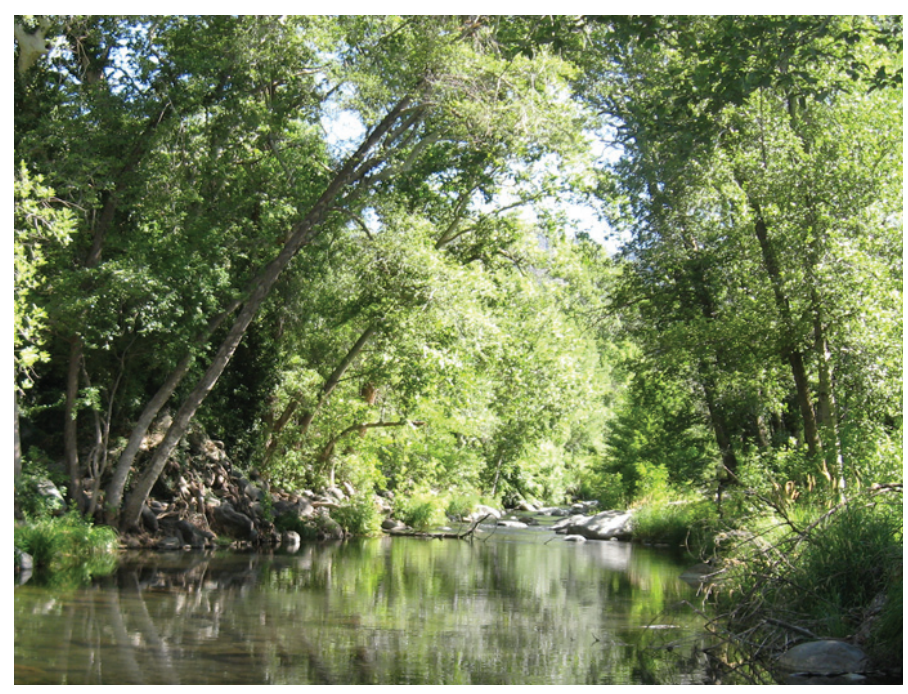

$46 \%$ of the delta's entire woody vegetation from 2006 to 2007.

\section{Identifying High-Quality Cuckoo Habitat}

As the changes at Lake Mead highlight, riparian ecosystems are dynamic and can change rapidly. USGS scientists are developing spatially explicit habitat models to examine how landscape-scale habitat variables affect cuckoo distribution. Spatially explicit habitat suitability models provide powerful tools for identifying habitat requirements of target species at multiple spatial scales. Such models not only help resource managers understand the ecology of a target species like the cuckoo, but also provide managers with site-specific information in the form of geographic information system (GIS) habitat maps. These models can identify the relative importance of individual variables (or combination of variables) in influencing the distribution of a species.

Understanding the habitat needs of the shy western yellow-billed cuckoo is an important step toward conserving this species. This USGS research demonstrates the key role that large, continuous areas of native riparian trees play in the cuckoo's selection of breeding habitat. These findings and the development of spatially explicit habitat models can help resource managers to conserve, manage, and restore the riparian habitats needed to ensure the survival of the disappearing western yellow-billed cuckoo.

\section{Matthew J. Johnson}

\section{References}

Holmes, J.A., Johnson, M.J., and Calvo, C., 2008, Yellow billed cuckoo distribution, habitat use and breeding ecology in the Verde Watershed of Arizona, 2003-2004; final report: Phoenix, Ariz., Arizona Game and Fish Heritage Program, 174 p.

Johnson, M.J., Durst, S.L., Calvo, C.M., Stewart, L., Sogge, M.K., Bland, G., and Arundel, T., 2008, Yellow-billed cuckoo distribution, abundance, and habitat use along the lower Colorado River and its tributaries, 2007 annual report: U.S. Geological Survey Open-File Report 2008-1177, 268 p.

\section{For more information contact: \\ U.S. Geological Survey Southwest Biological Science Center Colorado Plateau Research Station Flagstaff, Arizona 928-523-7764 or mjjohnson@usgs.gov}

This Fact Sheet and any updates to it are available online at http://pubs.usgs.gov/fs/2009/3091/ 